\title{
19. Visual Fine Art: Documenting change, influencing change, and subjected to change
}

\author{
John Reid
}

\section{Preamble to four propositions}

I begin with a selective chronology with pictures, mainly photographs. Every moment accounts for the state of things in the universe. A photograph is a sample of sequential moments. Photographs that are symptomatic of the times, emblematic of place, or foreshadow historical significance are notable markers in the universal ledger. Photographs, like memories, assist in the comprehension of time and with the perception of change.

\section{Mid-2012}

The Australian National University (ANU) radically changed its approach to music education. More than 30 positions at the University's School of Music were declared vacant in an unprecedented act of academic cleansing. A collective shiver like the feathering of kettledrums spread through the rest of the university community, to resonate most acutely in the School of Art as yet another exercise in the transformational change of creative art education in Australia (Figure 1). At the end of the previous decade, the Victorian College of the Arts had fought a sustained assault on its constitution. More recently, the technical and further education sector in New South Wales had written off its heritage in art education and thrown its programs into the jaws of the open market. 


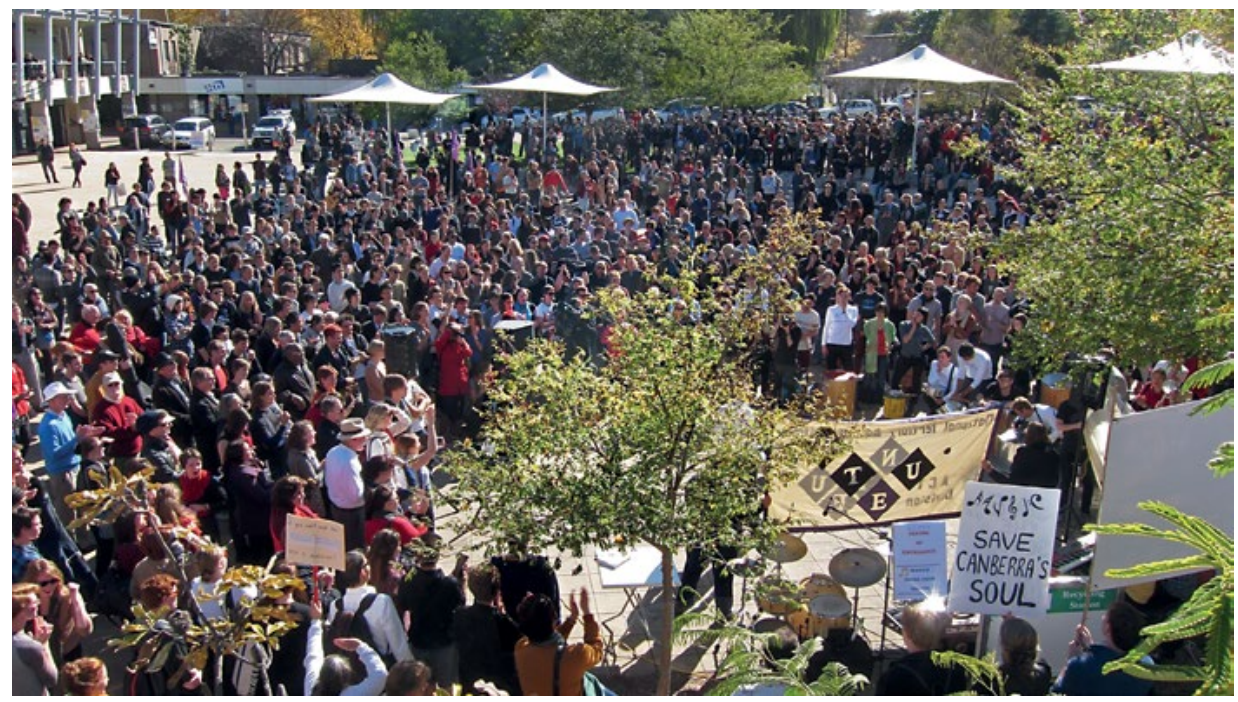

Figure 1 Protest jam, ANU, 14 May 2012.

A composite photograph of members of the Canberra community who have joined a rally called by the ANU Student Association and the ANU School of Music students and staff to protest a planned restructure of the ANU School of Music and associated staff redundancies.

Source: John Reid, 2012.

\section{Late 2012}

A group of climate scientists and visual artists prepares a submission to a city council on Australia's eastern seaboard to develop collaborative procedures for addressing climate change impacts with communities within the council's shire. Climate change scientists (as knowledge generators), artists (as aesthetic communicators) and community leaders (enthused with local wisdom) were part of the shire constituency. They were all keen to act as agents to encourage changes in behaviour that affects climate and that will enable us to cope with anticipated future climatic conditions (Figure 2). A comprehensive council strategic plan on climate change already existed, providing a framework for genuine engagement between all parties. An election and a change of councillors changed all of that-for the worse! 


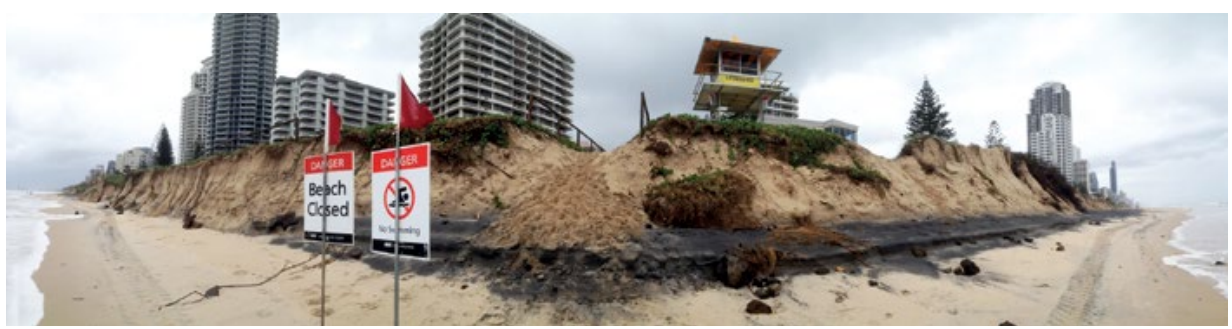

Figure 2 Queensland's Gold Coast, March 2013.

(iPhone panorama.)

The Gold Coast on Australia's eastern seaboard is, and will continue to be, a hot spot of change from sealevel rise and coincident severe climatic events.

Source: John Reid, 2013.

\section{February 2013}

During a table-stop conversation in a campus cafe, an old friend and professor of history recalled that 25 years ago the university's department of history had 25 tenured members of academic staff. This was a heartfelt lament compounded by the difficulty in making a direct comparison with how the discipline is now positioned in the university. Historians bed the dreams of visual artists (Figure 3).

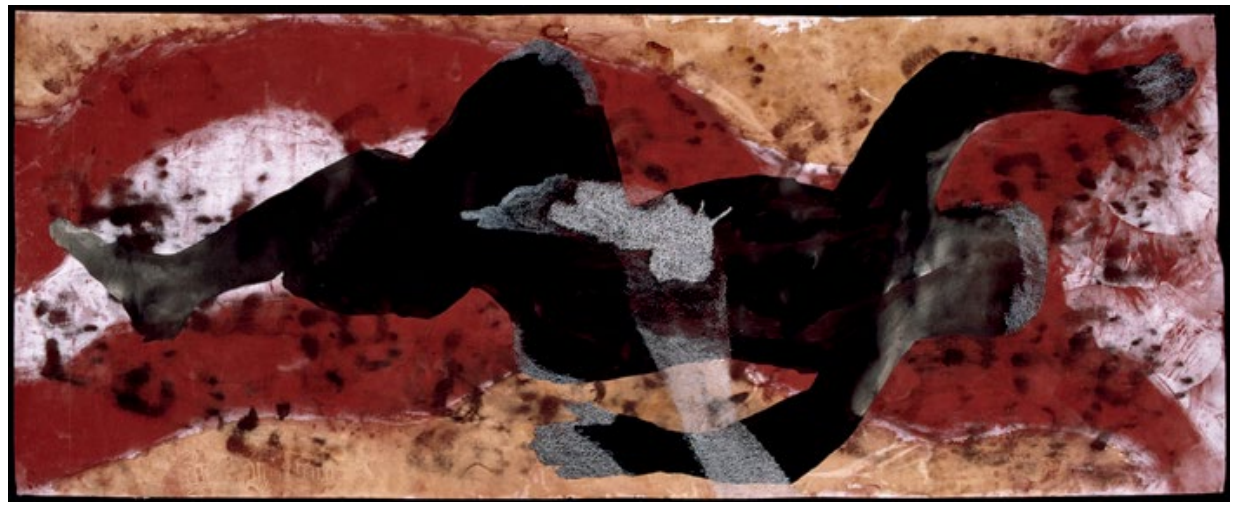

Figure 3 Deep in blood.

(Mixed media on card.)

Australian and Persian historical narratives informed this artwork.

Source: Nazanin Moradi, 2004.

\section{March 2013}

David Mabberley, executive director of the Royal Botanic Garden in Sydney (the oldest science institution in Australia), remarked on ABC Radio National that the discipline of botany — 'the plant voice' - had been lost altogether 
in some universities through its amalgamation with other lines of scholarly inquiry. This is a loss for the visual arts. The aesthetic visualisation of plants, that present themselves patiently for the eternal artist gaze, is enhanced by knowledge about their being and their role in the complex ecological systems of the Earth (Figure 4). Botanists, where are you?

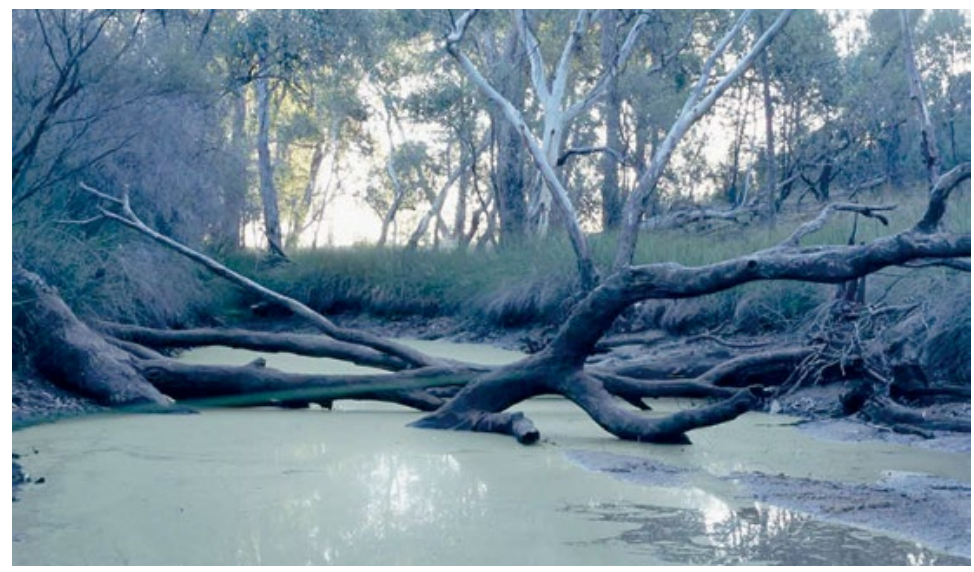

Figure 4 Bundock Creek-lowland chain of ponds.

(Digital print from colour transparency.)

The plant life in this picture is typical of an ecologically healthy Australian creek known as a lowland chain of ponds.

Source: Carolyn Young, 2004.

\section{April 2013}

My email server signals (in one of its last gestures before it changes to 'The Cloud') that a few seconds ago I had been contacted by Change.org. The contact informed me that an initiative harnessing the support of 41000 online signatures had delivered honour roll recognition for fallen peacekeepers by the Australian War Memorial Council. I was invited to click on green underlined text at the end of the email to start my own petition for change. As with practitioners in any other discipline (except, I suspect, information technology), artists can be found at every point on the spectrum of human response to electronic information technologies - from Luddite to early adopter. Almost all visual artists have now joined the digital revolution. Here is evidence. I still have an office pigeonhole (mailbox) down the corridor that now receives mail by snails. On my way to my office, to open my computer and read the email to which I have previously referred, I collected from my snailhole a printed invitation. On slender, glossy card the Australian National Capital Artists Inc (ANCA), a Canberra-run artist initiative, announced its most recent exhibition, ANCA NOW! (27 March - 
21 April 2013) showcasing the work of 27 of its current artists, amid a blaze of coloured pixels (Figure 5). The pixel motif also happens to be the graphic emblem on the organisation's logo.

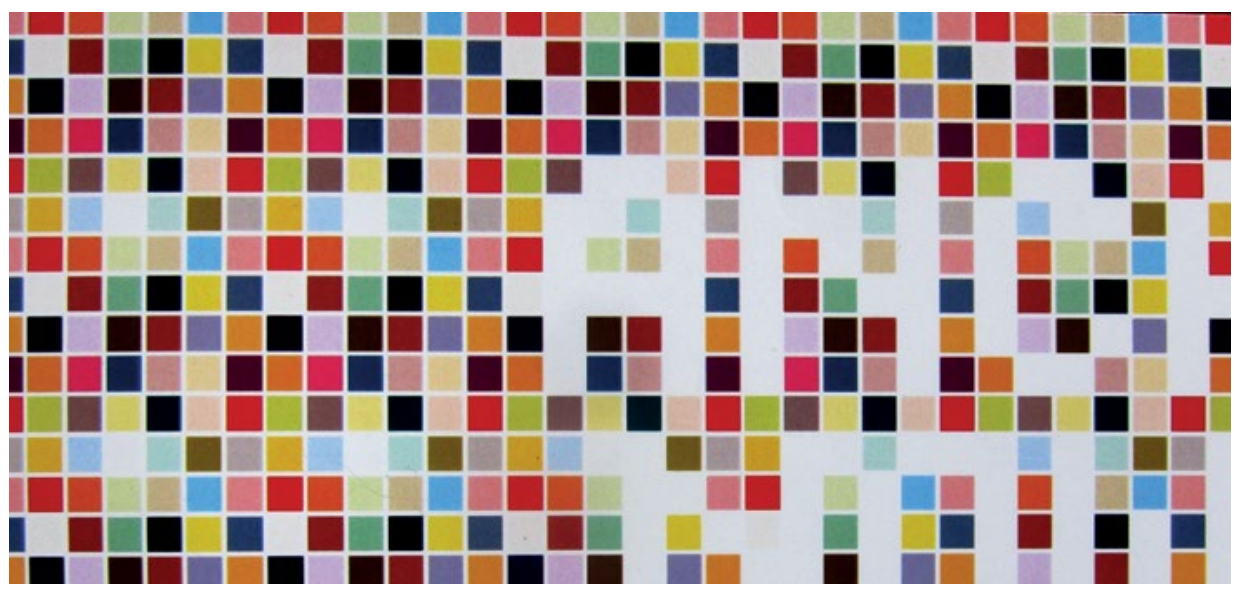

Figure 5 Invitation to ANCA NOW! (Australian National Capital Artists showcase exhibition, Canberra ACT), 27 March - 21 April 2013.

Source: Australian National Capital Artists, 2013.

\section{First proposition: Artists have changed into good collaborators}

This selective 18-month chronology of change in the discipline of the visual fine arts comes from the perspective of my individual practice as a fine artist, researcher and teacher. It is intended as a curtain raiser for my first proposition: that despite political and fiscal constraints, the subject matter of visual art inquiry is pervasive, more so than ever, and that there is an associated emergent inclination for visual artists to interact with other scholars. Essentially, the proposition is that artists are positioning themselves as good collaborators. This is substantiated by a number of cross-disciplinary research programs, emanating from within educational institutions of art themselves, and their positive reception within universities at large - especially from disciplines where research results have an immediate bearing on public policy. Developments manifest in many scholarly disciplines are now, as a matter of course, contenders for aesthetic visual registration.

Artists have not always been renowned for entertaining a comprehensive outlook or for being keen collaborators, as the clichéd notion of a solitary figure marooned in a garret in dialogue with art materials, alcohol and other drugs shows. Artists blessed with intuition, insight and active imaginations 
have always drawn content from experience as their life unfolds - and artists continue to do so today. But as schools of art changed from single purpose institutions to take their place in universities, artists found themselves at a table set as a smorgasbord of contemporary ideas. Added enthusiasm to make the most of this opportunity derives from the fact that subject matter is not taught as part of the curriculum in tertiary schools of art. There are some exceptions, where the medium is its own subject. But realistically, it is not possible to teach subject matter, not at the level of tertiary scholarship, to hundreds of students addressing as many different topics. In the teaching of a language, the focus is on vocabulary, grammar, pronunciation, idiom, writing and conversational skillnot on what the student might ultimately articulate with their new proficiency. The visual artists are taught likewise with an emphasis on how to express ideas visually and aesthetically — whatever the ideas might happen to be.

Field Studies, a program at the ANU School of Art, took full advantage of this expanded intellectual landscape. Developed in conjunction with the university's (then) Centre for Educational Development and Academic Methods in 1995, the School of Art Field Studies program provides for the input of expert knowledge into the creative process. This is achieved not only by tapping into disciplines across the campus but through a well-established procedure for canvassing a broad spectrum of wisdom and understandings residing in the community at large. More than 40 programs have been convened, resulting in a considerable audit of change with hundreds of aesthetic assessments (that is what works of art are) created for the cultural record throughout the eastern states of the country. During the last 15 years the program has changed too. In 2007 the program became the focus of the School of Art's first Australian Research Council Linkage project with the Murray-Darling Basin Commission (now Authority) as the collaborating organisation. Now, Field Studies is configured as a generic procedure with wide scope and application. Through the Field Studies program visual artists have engaged proactively with a considerable range of scholarly disciplines.

\section{Collaboration with music}

Music, from a visual art perspective, is highly valued; especially contemporary music composed and played in response to place. In this respect, currency between music and visual art develops when a place, and the forms of life it supports, is jointly investigated as a source of inspiration.

In Figure 6, the ANU School of Music Contemporary Music Ensemble directed by Tor Frømyhr, Head of Strings in 2009, prepares for a public concert of impromptu performances inspired by field research around Benalla, Victoria. The venue was the Benalla Art Gallery where an exhibition referencing the 
Benalla region by artists from the ANU School of Art was exhibited. A highlight of the evening concert was an impromptu performance by the ensemble, inspired by the artwork on the gallery walls. Figure 7 is an artwork that was played as a graphic score by the ensemble at that performance.

The music and the visual art were intentionally pitched to encourage the community to reflect on the attributes of (their) place as a prerequisite for shaping public policy. As the world inexorably changes, formulation of public policy never ends.

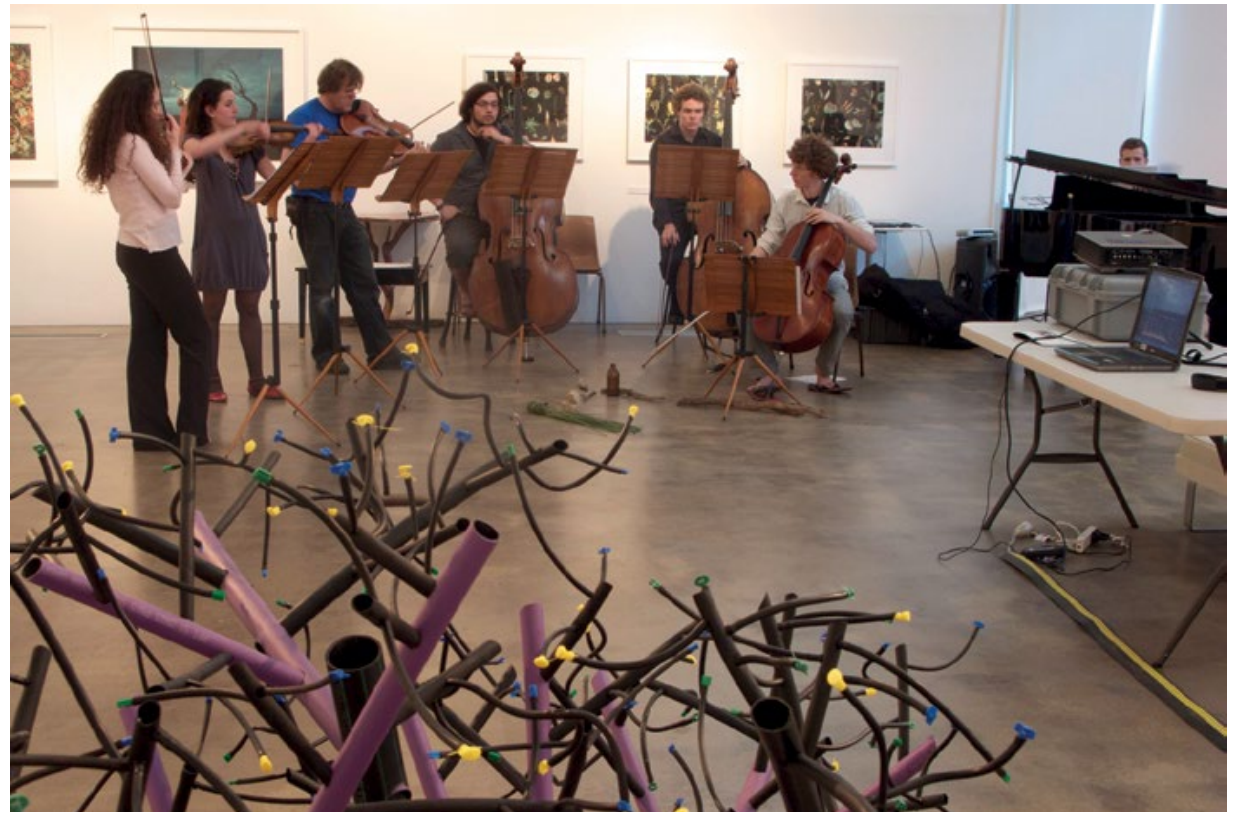

Figure 6 ANU School of Music Contemporary Music Ensemble in rehearsal, Benalla Art Gallery, Victoria (Tor Frømyhr third from left).

Source: John Reid, 2009.

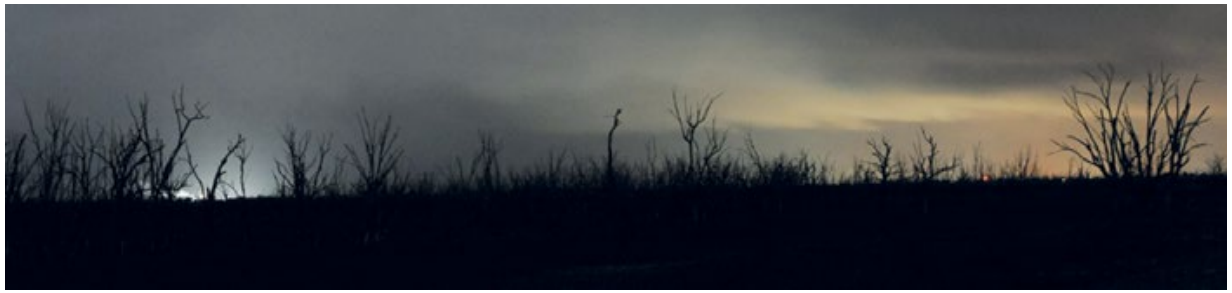

Figure 7 Night photograph of emissions around Benalla (detail).

(Digital photograph.)

Source: Marzena Wasikowska, 2009. 


\section{Collaboration with history}

Historians, and in particular oral historians, provide visual artists with narrative content that can significantly charge their imaginings. In the past, field research programs have commissioned oral histories from writers recruited from ... anywhere. Dick Aitken, a Canberra writer pictured on the Goulburn River floodplain, Shepparton, Victoria, is taking notes in conversation with Aboriginal Yorta Yorta Elder Ella Anselmi on an ANU School of Art Field Studies program in 2006 (Figure 8).

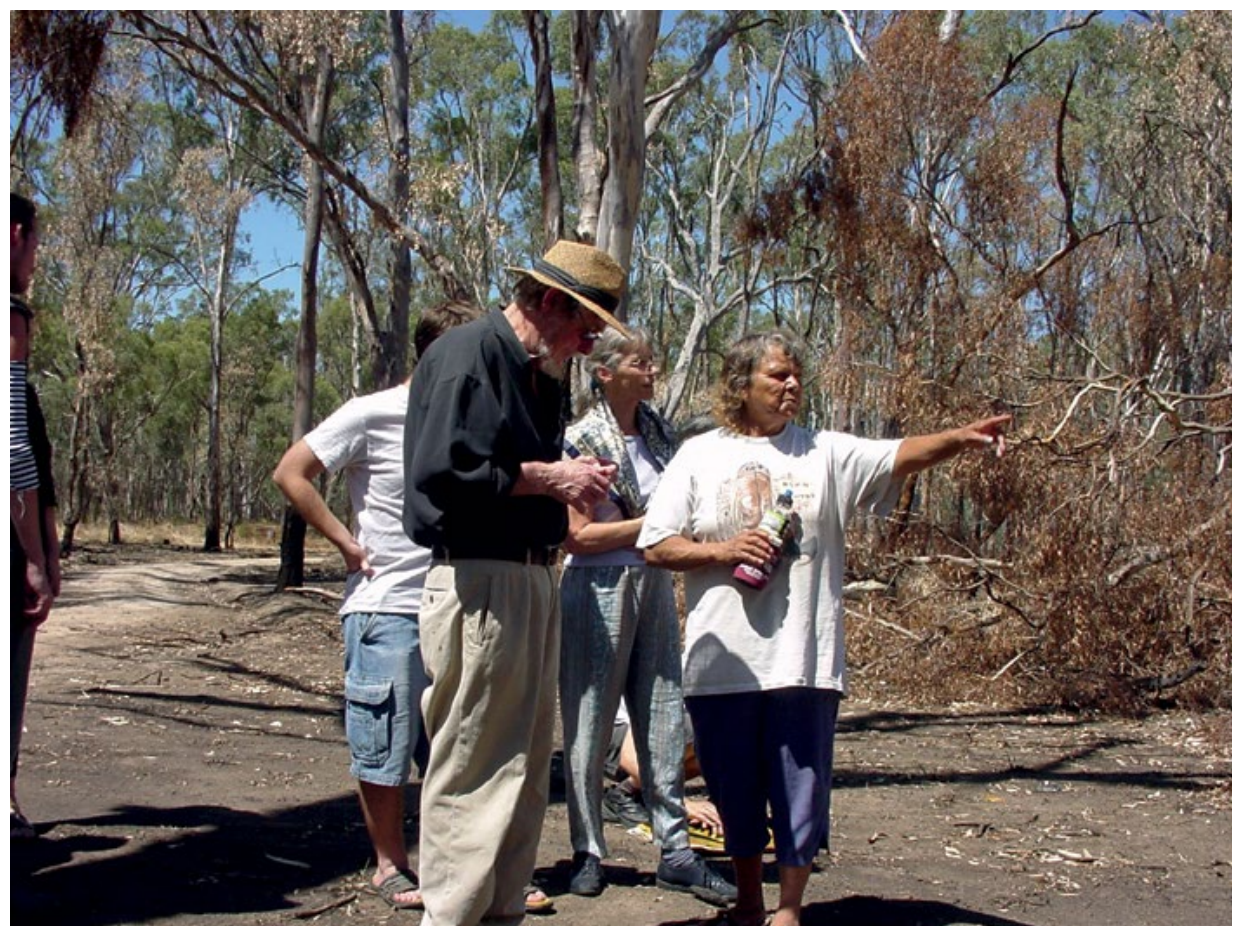

Figure 8 Canberra writer Dick Aitken records knowledge of place from Yorta Yorta Elder Ella Anselmi (right), Shepparton, Victoria.

Source: John Reid, 2006.

Dick's oral history interviews provided valuable references for artists. The emotionally moving Indigenous narratives such as the ones that Ella told inspired the artwork reproduced here as Figure 9.

Now, ANU offers a graduate course in oral history, life stories and memory. That's a change! Let's bring these students and visual artists together. 


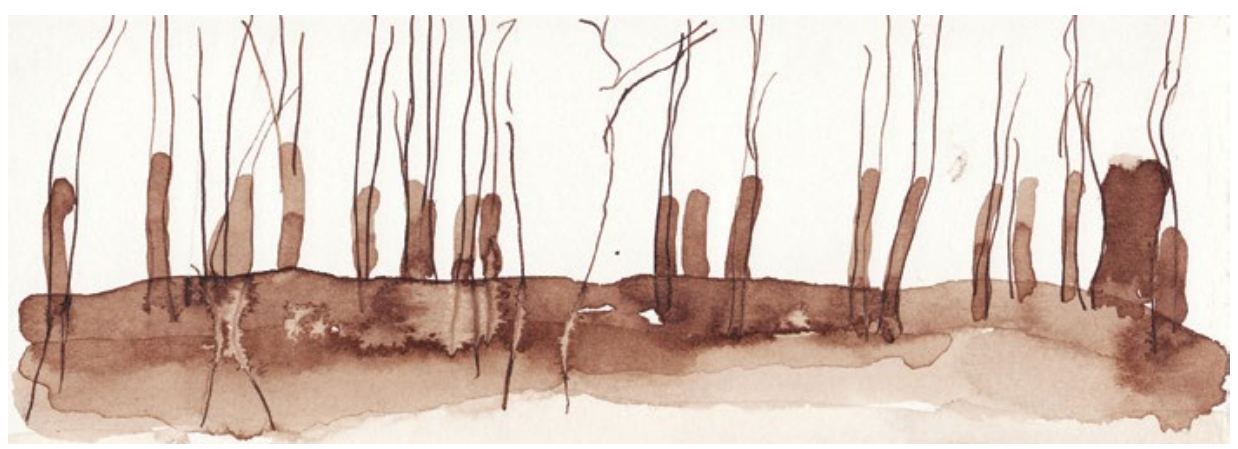

Figure 9 Floodplain, series 1-4 no. 1 (detail).

(Ink and wash on rag paper.)

Source: Antonia Aitken, 2006.

\section{Collaboration with cultural relations}

A collaboration between visual artist Dr Frank Thirion of Canberra and Indigenous Elder John Williams Nubbarow of the Iwaidja people, Northern Territory, during fieldwork in 2011 at Calperum Station near Renmark, South Australia, generated a painting titled Shadowland and a sculpture titled Guuldok by Thirion, who was inspired by Nubbarow's recounting of the Iwaidja 'lightning spirit' story (Figure 10). Regrettably a joint undertaking such as this one is a rare component of the Field Study program. For this to happen more often the scheduling of the program's field trips would need to be open-ended.

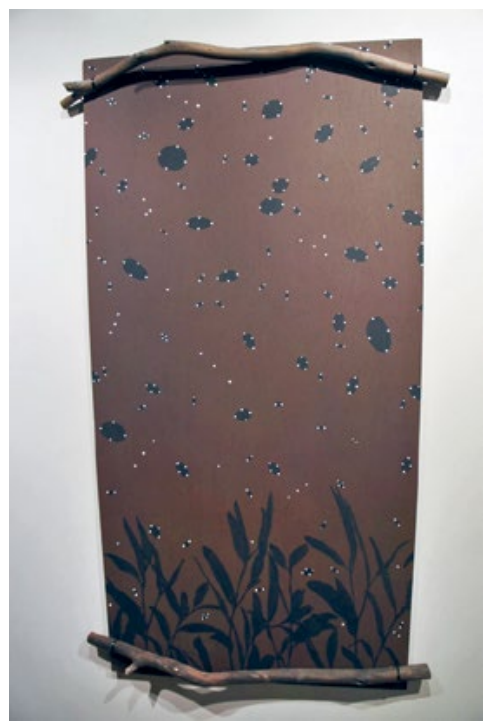

Figure 10a Shadowland.

After John Williams Nubbarow, Iwaidja people's 'lightning spirit' story.

(Natural pigments on wood.)

Source: Frank Thirion, 2011.

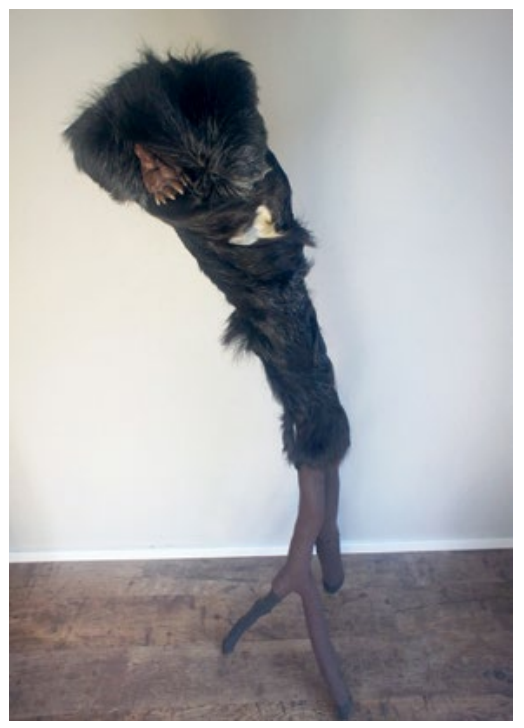

Figure 10b Guuldok.

After John Williams Nubbarow, Iwaidja people's 'lightning spirit' story.

(Natural pigments, feral goat pelt on wood.)

Source: Frank Thirion, 2011. 


\section{Collaboration with biological and earth sciences}

Knowledge from botany, zoology, soil science and landscape ecology combines with art sensibilities at a gathering of landscape ecologists and visual artists in a contested forest near Braidwood, New South Wales, in 1996 (see Figures 11 and 12).

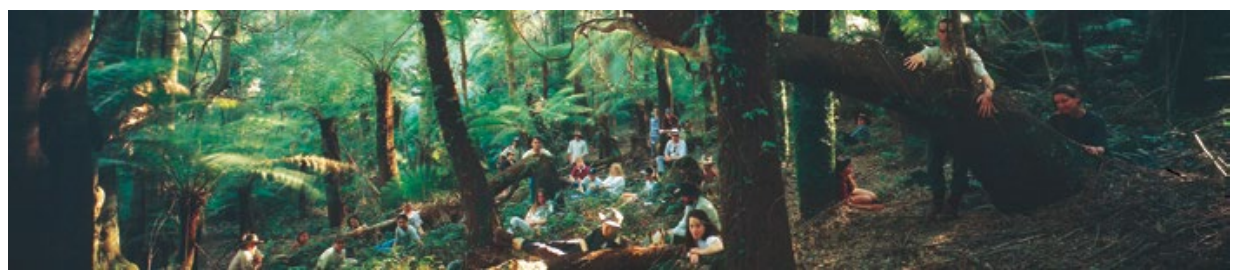

Figure 11 Professor Brendan Mackey (right of centre, wearing a white hat), formerly of the ANU Fenner School of Environment and Society, with his Landscape Ecology class and artists from the ANU School of Art Field Study program, in a patch of forest dominated by plumwood (Eucryphia moorei) and tree ferns (Dicksonia antarctica), Monga State Forest, NSW.

Source: John Reid, 1996.

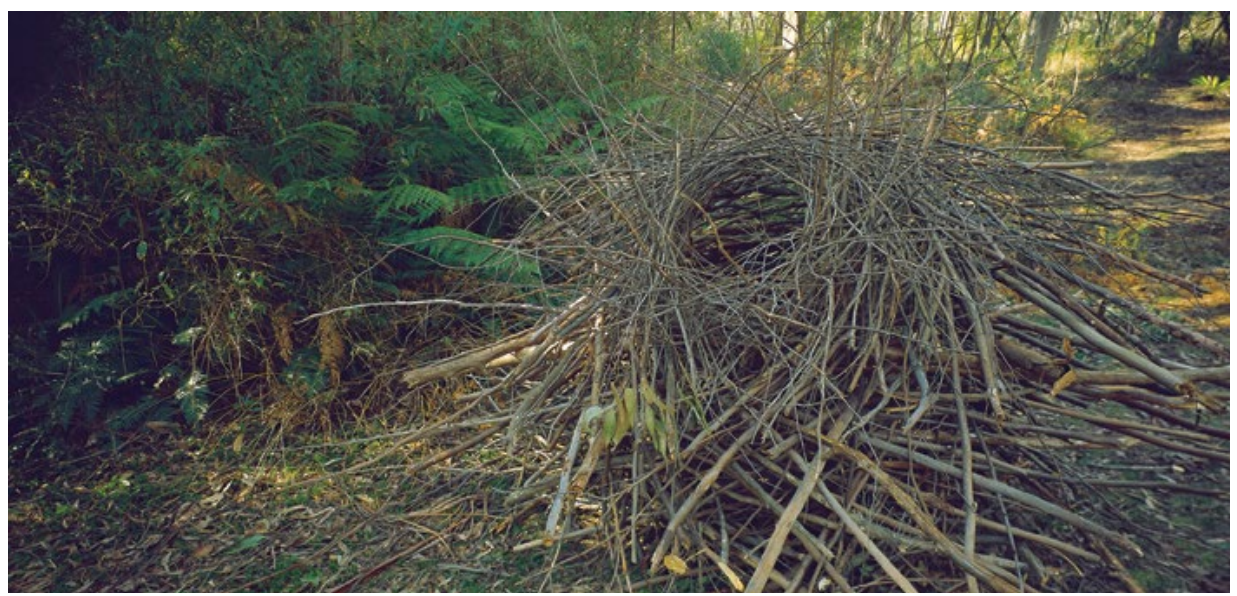

Figure 12 Untitled.

(Eucalypt branches, twigs and bark). Monga State Forest, NSW. Source: Dan Maginnity, 1996. Photograph by John Reid, 1996.

There in Monga, the scientists mesmerised the artists with their discerning investigations of the physical and biological relationships of the forest - with their analytical approach, descriptive terminology and narratives of symbiotic relationships. The artists reciprocated with beguiling, opinionated imagery that drew heavily on the intellectual input from the scientists' ecological assessments, as well as on a sustained, personal immersion in the quality sensory environments of the forest. Supported by accounts from both the arts 
and the sciences, a resilient local community changed the fate of the forest from becoming a chipped commercial commodity to a national park that celebrated Monga's forests as an irreplaceable asset of natural heritage. The forests of Monga flourish today as a wonderful resource available to the educational institutions of the national capital not far away.

\section{Collaboration with the environmental sciences}

Commensurate with the contests over the fate of Monga forests was a temporary change in ANU's structure that facilitated a widening of perspectives in the visual arts within the university. In August 2001, a suite of 12 national institutes was superimposed over the entire university. Academics were invited to elect membership to the institute with which they identified in terms of their research and teaching interests. Many disciplines within ANU were represented in the membership of the National Institute for Environment. There was a quirk in funding arrangements for this Institute and extra money fell into its coffers. Cash is a very effective agent for the acceleration and realisation of simmering attitudinal change. Idealism was dealt a budget line. Artists from the School of Art began working in earnest with scientists of all complexions through the Institute for Environment. As shown in Figure 13, sculptor, Wendy Teakel, ANU School of Art, produced a sculptural work informed by consultations with human ecologist David Dumaresq, ANU Fenner School of Environment and Society.

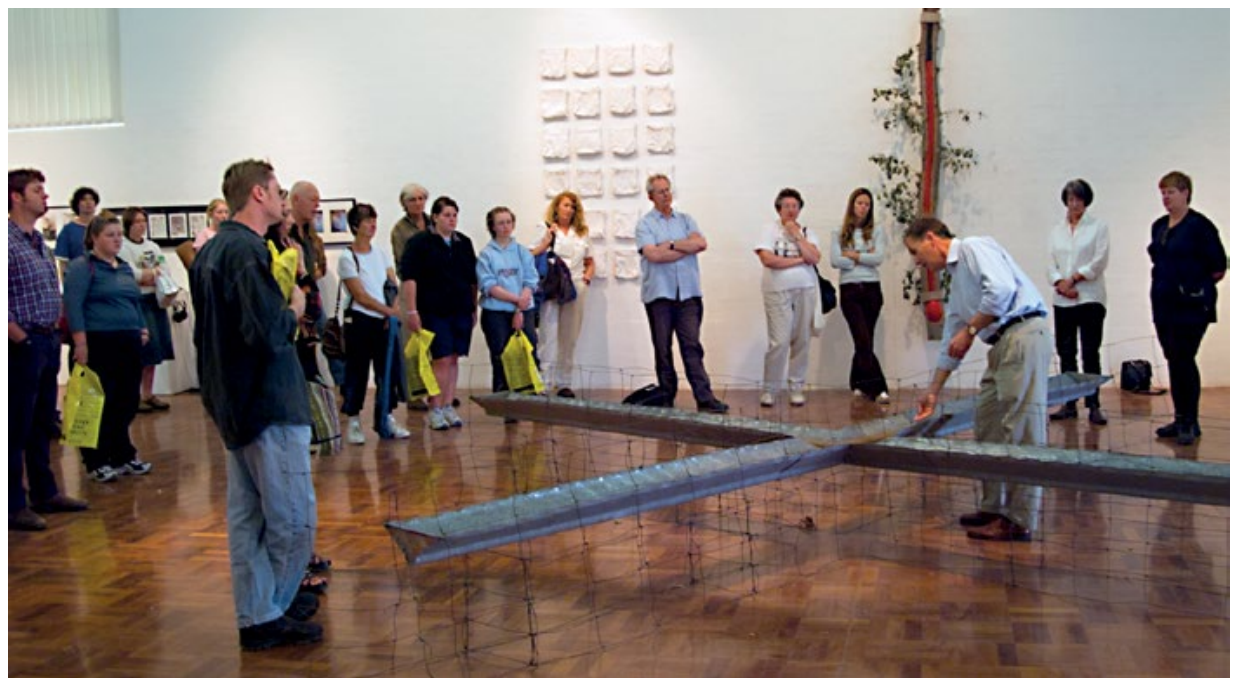

Figure 13 Artist Wendy Teakel (far right), ANU School of Art, at a public floor talk with her sculptural work in the exhibition Factor of Ten: A Future Worth Having, in 2002.

David Dumaresq (third from right), ANU Fenner School for Environment and Society, discusses the work that he helped inform.

Source: Marzena Wasikowska, 2002. 
With the 'Factor of Ten' event, the prevailing paradigm of artists tinkering with scientific equipment in a laboratory to the bemusement of all gave way to formalised, genuine collaborations. Artists began to create works that were informed by scientists through one-on-one consultations, that were instructive as well as being aesthetically and emotionally powerful, and that were publicly exhibited in conjunction with conceptually related scholarly events such as conferences and seminar programs. The public was engaged in a program of gallery floor talks where it was difficult to distinguish the presenting artists from the scientists. There was no shortage of spirited, knowledgeable discussion. There was time for genuine contemplation by all concerned. This was the collaborative agenda that laid an enduring foundation still influential today. Visual aesthetic imagery informed by science brings a human, high-fidelity, emotional dimension to science communication.

\section{Second proposition: Artists are good archivists of change}

My second proposition is that artists are good archivists of change. In fact, I would argue that the fine arts deliver artefacts from which come the most eloquent, manifestly human punctuations of time. A fine artwork, primarily consisting of exquisitely related forms, subsequently evokes (exquisitely again) the conceptualisation of other relationships. In this respect the production of artwork entails a creative commitment without compromise within the gambit of human capability. The perception of fine artwork literally electrifies the brain. One is irrevocably changed. Think of Picasso's Guernica (1937), as it is perceived now, and Peter Dombrovskis' Morning mist, Rock Island Bend, Franklin River, Tasmania, 1979 (1979), as it may have been perceived in 1983, when the (ultimately successful) campaign to stop a dam project was at its height.

\section{Third proposition: Fine artworks can be potent agents for or against change}

To further complicate the matter, fine artworks are not just calibrations of change; they can be potent agents for or against it-proposition three. Famous Australian examples are Russell Drysdale's austere outback paintings commissioned in the late 1940s to underscore the public acceptance of the Snowy Mountains Scheme (a Federal imperative to irrigate), and Dombrovskis' Franklin River photograph mentioned above, which was commandeered into 
the 1983 election campaign to politically undermine the damming of a river (a state imperative to generate hydroelectricity). Drysdale's paintings promoted change; Dombrovskis' photograph arguably prevented it.

\section{Fourth proposition: A prediction that artists will expand their competence in research methods and project management}

My fourth proposition about change in the visual arts is a prediction: artists will become proficient in a broad range of research methods, and competent (perhaps reluctantly) in the finer points of project management. Although visual artists will continue to collaborate with scholars in disciplines as outlined above, other aesthetic operatives will dominate the creative arts scene. People who have postgraduate qualifications in both the visual arts and other fields of expertise are emerging in increasing numbers. It is not uncommon to find artists combining well-developed aesthetic sensibilities with the scholarly exercise of scientific or historical methods of inquiry. Research-focused schools of art will induct artists into the investigative methods of the social sciences and develop more rigorous action research procedures for creative production. Traditional methods for the confident exercise of intuition and the imagination for the formulation of concepts from quality sensory encounters with the world will still hold their ground. Schools of art will persist as enclaves where proof is not pre-eminent. But the dollar will rule. Collaborative research of social consequence usually involves considerable amounts of publicly accountable money. Aesthetically astute, visually literate researchers who are also competent project managers will score the prize.

\section{Conclusion}

Change will undoubtedly peg my four propositions to the early part of the twenty-first century. Collectively they assert that visual fine artists are influential in the dynamics of change, as immersed scholarly collaborators and discerning archivists; and that they are set to play more equitable roles in publicly funded research in the social sciences. In the course of any settlement in which I am held to account for these views, I will simply appeal to a fifth proposition: that the medium in which visual artists are most eloquent is a visual one and reliant, if at all, on a mere title of text. As a pre-emptive strike, see my ace card (Figure 14) in the case for change from a visual art perspective. 


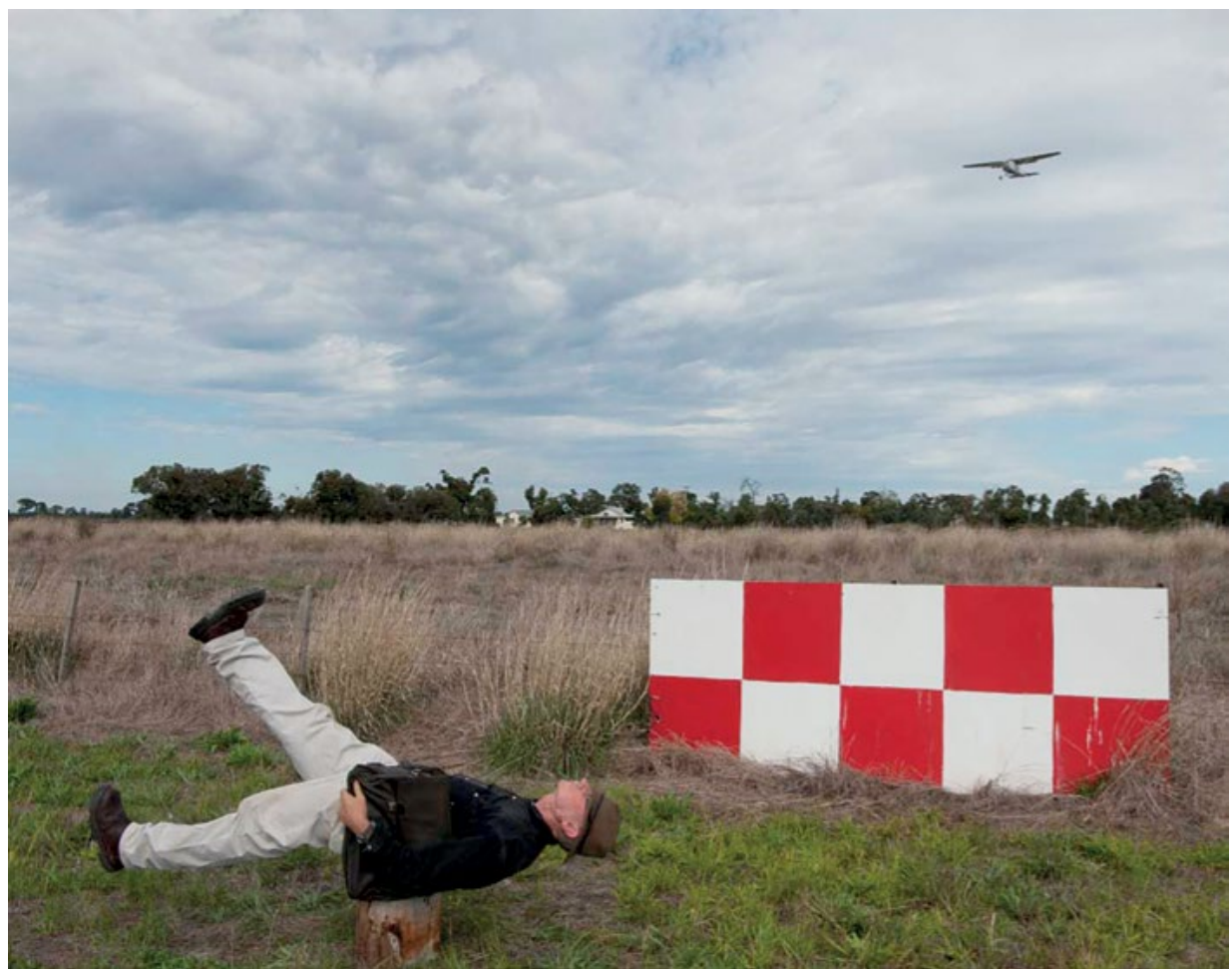

Figure 14 Walking the solar system, Shepparton Vic.

(Digital photograph.)

John Reid, 2012. Walk duration: one minute. Distance travelled: approximately 1,800 kilometres relative to the sun. Walk adviser and camera operator: Marzena Wasikowska.

Source: John Reid, 2012. 
This text is taken from Change! Combining Analytic Approaches with Street Wisdom, edited by Gabriele Bammer, published 2015 by ANU Press, The Australian National University, Canberra, Australia. 